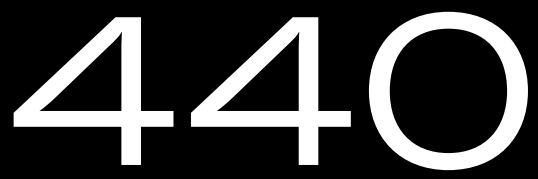

A biblioteca elementar, de Alberto Mussa

Juliana Cunha e

Júlio César de Oliveira Vellozo

DOI 10.11606/ISSN.2447-8997.TERESA.2020.158634 


\section{Um romance de códigos}

ALBERTO MUSSA.

A biblioteca elementar.

Record, 2018.
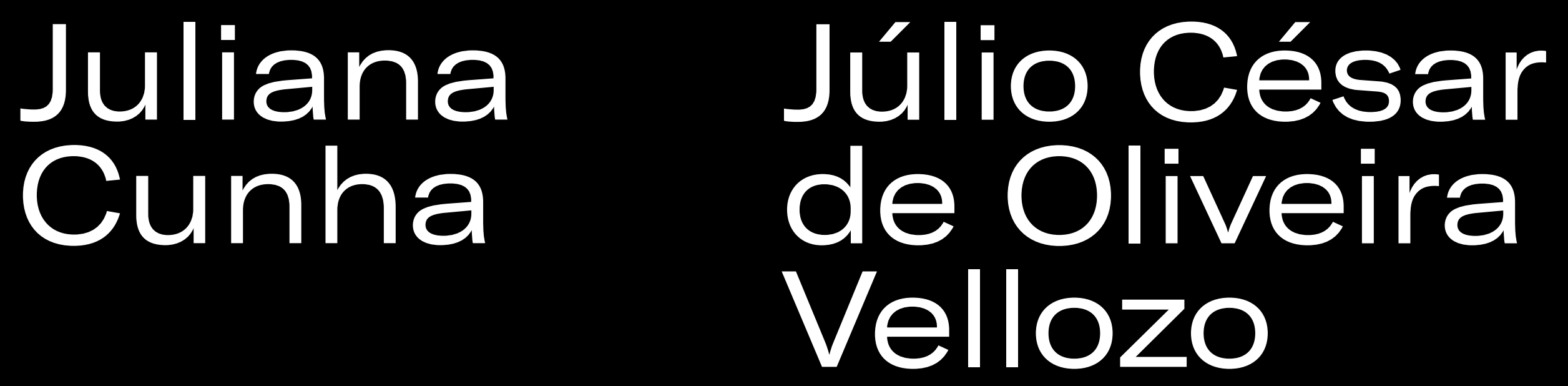


$$
\text { ru }
$$


visam ao público local. Ela também pode ilustrar uma perda de importância do Rio de Janeiro, se não do Brasil como um todo, enquanto dado e matéria de certa fatia da literatura nacional. O Brasil não é conhecido, e não se supõe do leitor médio qualquer familiaridade com esse terreno. Se diferentes ondas e expressões regionalistas buscaram mapear e desvendar a peculiaridade nacional e de suas especificidades, o bom-tom de hoje parece ser fingir que o Brasil é um país como outro qualquer e, embora isso não funcione em parte alguma, o arremedo fica menos óbvio situando as narrativas em uma São Paulo cênica.

Em seu autointitulado "compêndio mítico do Rio de Janeiro", Alberto Mussa rompe com esse pacto ao apresentar narrativas que pressupõem algum grau de conhecimento da paisagem carioca, e que se abrem ao leitor de acordo com sua compreensão acerca da história nacional e das histórias populares. Composto de cinco ${ }^{1}$ romances que se propõem a percorrer quatro séculos de Brasil - do começo da colonização (1500-1815) à República Velha (1889-1930), ainda que não em ordem cronológica -, o ciclo se fecha com $A$ biblioteca elementar, que ora resenhamos. O conjunto oferece um panorama da história social carioca, com a combinação e o conflito de suas diferentes etnias, classes, credos e dos mistérios que constituem a matéria mítica local, forjada no choque imaginativo entre

1 O trono da rainha Jinga (1999), O senhor do lado esquerdo (2011), A primeira história do mundo (2013), A hipótese humana (2017) e A biblioteca elementar (2018), todos pela editora Record. a fé católica, rituais indígenas e religiões de matriz africana. Ambientado no século xVIII, o romance se volta para o microcosmo dos ciganos que teriam habitado a rua do Egito (nome antigo e fictício da atual rua da Carioca), onde se dá o crime que organiza o enredo.

Não há na historiografia nenhum registro convincente de que a região tenha de fato sido habitada por ciganos, mas a estruturação do material permite a verossimilhança, quando não a plausibilidade. Isso porque o autor trabalha com um relato que mistura a incorporação de grandes fatos reais atuando no pano de fundo, invenções razoavelmente verossímeis como mote da narrativa e interlocuções praticamente literais com documentos históricos - a exemplo da história da escrava do convento franciscano, impedida de dormir na ordem porque contaminaria o ambiente como um todo (oriunda da ideia tomista de que a mulher seria o agente ativo do pecado e seu corpo um elemento de permanente corrupção); e de toda a passagem do lesbianismo entre Maria Cabra e Maria Pinima, basicamente transposta de relatos inquisitoriais como aqueles reunidos em Confissões da Bahia: Santo Ofício da Inquisição de Lisboa (Companhia das Letras, 1997, organização de Ronaldo Vainfas).

Embora Mussa apresente sua obra como sendo um romance policial, o livro não parece cumprir os pressupostos que costumam caracterizar o gênero. Primeiro, não há na história nem policial nem detetive, ou mesmo alguém que cumpra esse papel, como ocorre com os monges de $\mathrm{O}$ 
nome da rosa, por exemplo. Segundo, os fatos, as circunstâncias e seus responsáveis são elucidados de antemão: há um crime do qual conhecemos tanto a vítima quanto o perpetrador, e ao qual assistimos através da narração. $\mathrm{O}$ que desconhecemos é a motivação não do crime, mas da vítima, ao bater à porta de seu assassino. Outra característica que afasta $A$ biblioteca elementar do gênero detetivesco é que o fio que guia a leitura - aquilo que faz o leitor prosseguir no texto - não é a curiosidade em saber o desfecho do crime colocado, mas curiosidades sobre pequenos enigmas que vão sendo apresentados e desvendados ao longo do romance.

É, na verdade, um livro calcado na decifração e em exercícios lógicos, que guarda semelhanças com o relato policial por seu caráter analítico e racionalizante. Porque há racionalidade na mítica carioca, nas adivinhações ciganas e nas predições de todo tipo que vão guiando labirinticamente o leitor de Mussa. $O$ desvendamento sucessivo de mistérios laterais peça a peça vai formando um amplo mosaico do crime, sem o clássico momento da revelação totalizante que esclarece tudo a todos, em geral feita por um detetive cujas venturas e desventuras guiaram a história, modelo encontrado em muitos dos romances policiais. Aqui, a descoberta final se dá como conclusão pessoal de personagens que não têm interesse em fazer uma revelação pública, e cuja constatação altera a compreensão da identidade da vítima, e não do assassino.

O enredo se inicia na noite do dia 13 de novembro de 1733, quando uma mulher, oculta em um hábito franciscano, sai às escondidas do Cemitério dos Pretos, no Convento de Santo Antônio, em direção à rua do Egito. À margem do traçado da cidade e composto por duas dezenas de casas simples, o logradouro era morada de ciganos e cristãos-novos, de gente que ambicionava entrar para o desenho oficial do Rio de Janeiro ou que buscava refúgio em suas bordas. No caminho, a mulher testemunha um crime: um homem bate à porta de outro e inicia uma discussão sussurrada sobre o conteúdo de um papel. Há uma luta breve e quem tomba é o visitante, desarmado de sua pistola. A mulher, também moradora daquela rua, conhece os dois e sabe do que se trata o papel. Justamente por isso, não compreende por que o morto foi mostrá-lo ao vizinho.

Como quase todos os personagens, a testemunha desse crime inicial também tem o que esconder, mas, como o narrador nos alerta desde o começo, "dentre os crimes que perpassam o livro, apenas um é de fato relevante". "Contraditoriamente, esse crime é o único que não acontece." O delito que não ocorreu, mas que engendra o enredo, é a "história elementar da humanidade, que está em todas as mitologias: aquela que narra a traição da Mulher". A grande graça do livro é construir uma trama que gira em torno do que seria a maior biblioteca particular do Rio de Janeiro à época, recheá-la de subtramas de ascensão social, conflitos de identidade, enigmas árabes, referências astrológicas, metafísica tupi, macumbas e de tudo aquilo que mais de um século 
depois daria na criação da umbanda, mas fazer com que, em meio a tantas possibilidades, o busílis da questão seja só um homem que não sabe ler diante da única história que seu limitado repertório conseguiu imaginar: a da traição feminina.

A questão central do romance são os códigos e suas interpretações, e o destino das personagens é traçado a partir de sua habilidade ou inabilidade em compreendê-los e manuseá-los. As ciganas vivem da decifração e manipulação de cartas, de linhas das mãos. Piolho, o senhorio à la João Romão, tenta sua ascensão social como rábula, e busca sua entrada no Santo Ofício baseado no fato de que a tipificação de sua raça seria falha nas regras da Ordem. Leonor Rabelo e Bernarda Moura disputam interpretações para saber quem seria a esposa legítima e quem seria a outra. A mesma Bernarda fia-se numa interpretação para se declarar viúva. Há códigos culturais, comportamentais, religiosos, penais. Uma mulher andando sozinha na rua deixara de ser crime há pouco, mas continua levantando suspeitas por desobedecer a códigos sociais. A leitura é hoje o código básico, mas seu domínio à época era limitado. Saber decodificar as letras tampouco garante o entendimento de materiais como, por exemplo, o pasquim dos Três Cegos. No romance, testemunhamos a alfabetização de uma Leonor que ainda engatinha nos significantes, mas já é mestre nos significados.

O narrador é um sujeito temporalmente apartado dos fatos narrados e que pratica uma espécie de onisciência seletiva de cunho geográfico. Nela, seu conhecimento é praticamente total, porém circunscrito ao Rio de Janeiro. Um passo para fora dos limites da cidade e o narrador perde o rastro de seus personagens. "Não sei o que se dá em Minas, porque meu romance é sobre o Rio de Janeiro", afirma em determinado momento, ao justificar sua ignorância em relação ao destino de Lázaro Roriz, que partiu em busca de ouro. Em outra passagem, não consegue esclarecer a origem de duas personagens "porque não me pronuncio sobre fatos transatlânticos".

Além de limitar os conhecimentos do narrador, a geografia também atua como procedimento narrativo, fazendo com que o livro ganhe ares ora de um voo panorâmico sobre a cidade, ora de uma caminhada por suas vielas. Isso é particularmente perceptível no primeiro capítulo, construído em torno do trajeto da testemunha Leonor até o local do crime. Assim como a rua e o próprio Rio de Janeiro, o crime brota do Chafariz do Carioca, que funciona como um ponto central do qual tudo se origina. Isso porque o Rio Carioca é tomado como rio mítico, fundador da cidade e razão de seu gentílico. Beber de suas águas teria motivado a sedentarização dos ciganos que fundam a rua do Egito, algo que se explicaria tanto pela magia atrativa do rio quanto pelo caráter maleável do Rio de Janeiro, uma cidade menos fixa que as outras.

Trata-se de um livro sobre o Rio escrito na contramão da perda de importância da cidade. Toda a narrativa dá ao lugar uma dimensão mítica. A rua do Egito, que começa com o casamento de um 
cigano com uma não cigana (espécie de Ceci e Peri da Carioca), termina onde hoje se situa o Bar Luiz, o que parece retirar o relato de Mussa do tempo teleológico, aproximando-o do tempo do narrador. Enquanto, no plano mítico, o Rio é enaltecido, no tempo compartilhado pelo leitor e pelo narrador, a mesma rua assiste à luta do Bar Luiz, um dos mais tradicionais da cidade, para manter as portas abertas em meio ao ocaso do Rio de Janeiro.

Nesse grande elogio do Rio, Mussa fala de um lugar que não seria normal. De um espaço meio mágico, mas que é narrado de modo a normalizar o fantástico, a transformar o maravilhoso em cotidiano, um pouco na chave das composições de Aldir Blanc sobre a vida carioca. Com uma construção inventiva e esteticamente potente, $A$ biblioteca exemplar é um ponto fora da curva da literatura brasileira contemporânea tanto em matéria quanto em fatura artística.

JULIANA CUNHA é doutoranda de Teoria Literária e Literatura Comparada, mestre em Teoria Literária e Literatura Comparada, bacharel em Letras e graduanda em História pela USP.

JÚLIO CÉSAR DE OLIVEIRA VELLOZO é professor da Faculdade de Direito da Universidade Presbiteriana Mackenzie e da pós-graduação da Faculdade Autônoma de Direito. Pós-doutor em direito pela usP e pela Universidade de Salamanca, doutor em história social, mestre em estudos brasileiros e bacharel em história pela USP. 